\title{
Origin and evolution of eukaryotic apoptosis: the bacterial connection
}

\author{
EV Koonin ${ }^{\star, 1}$ and L Aravind ${ }^{1}$ \\ 1 National Center for Biotechnology Information, National Library of Medicine, \\ National Institutes of Health, Bethesda, MD 20894, USA \\ * Corresponding author: EV Koonin, National Library of Medicine, National \\ Institutes of Health, Bldg. 38A, Rm. 5N503 (5th floor) 8600 Rockville Pike \\ Bethesda, MD 20894, USA. Tel: +1.301.435-5913; Fax: $+1.301 .435-7794$ or \\ +1.301.480-9241; E-mail: koonin@ncbi.nlm.nih.gov
}

Received 10.11.01; accepted 21.11.01

Edited by G Melino

\begin{abstract}
The availability of numerous complete genome sequences of prokaryotes and several eukaryotic genome sequences provides for new insights into the origin of unique functional systemsoftheeukaryotes.Severalkeyenzymesoftheapoptotic machinery, including the paracaspase and metacaspase families of the caspase-like protease superfamily, apoptotic ATPases and NACHT family NTPases, and mitochondrial HtrAlike proteases, have diverse homologs in bacteria, but not in archaea. Phylogenetic analysis strongly suggests a mitochondrial origin for metacaspases and the HtrA-like proteases, whereasacquisitionfromActinomycetesappearstobethemost likely scenario for AP-ATPases. The homologs of apoptotic proteins are particularly abundant and diverse in bacteria that undergo complex development, such as Actinomycetes, Cyanobacteria and $\alpha$-proteobacteria, the latter being progenitorsofthemitochondria.Inthesebacteria,theapoptosis-related domainstypically form multidomain proteins, whichare known orinferredtoparticipateinsignaltransductionandregulation of geneexpression.Someofthesebacterialmultidomain proteins contain fusions between apoptosis-related domains, such as AP-ATPase fused with a metacaspase or a TIR domain. Thus, bacterial homologs of eukaryotic apoptotic machinery components mightfunctionally and physically interact witheachother asparts ofsignaling pathwaysthatremaintobeinvestigated.An emerging scenario of the origin of the eukaryotic apoptotic system involves acquisition of several central apoptotic effectors as a consequence of mitochondrial endosymbiosis and probably also as a result of subsequent, additional horizontal gene transfer events, which was followed by recruitmentofnewlyemergingeukaryoticdomainsasadaptors. CellDeath and Differentiation (2002) 9,394-404. DOI: 10.1038/sj/ cdd/4400991
\end{abstract}

Keywords: eukaryotic apoptosis; bacteria

Abbreviations: HGT, horizontal gene transfer; PCD, programmed cell death; TIR, toll-interleukin receptor; AIF, apoptosis-inducing factor

\section{Programmed cell death: sine qua non of a multicellular state}

The origin of eukaryotes and the advent of multicellularity are momentous evolutionary transitions that involved invention of several fundamentally new functional systems. The eukaryotic chromatin remodeling machinery, the cell cycle regulation systems, the nuclear envelope, the cytoskeleton, and the programmed cell death (PCD, or apoptosis) apparatus all are such major eukaryotic innovations, which do not appear to have direct prokaryotic predecessors. ${ }^{1}$ Although bacterial cells commit suicide under certain circumstances, for example, during fruiting body formation in Myxobacteria, these mechanisms do not appear to be essential for the survival of prokaryotes in general and their molecular build-up seems to be unrelated to that of eukaryotic apoptotic machinery. ${ }^{2-4}$ In contrast, in multicellular eukaryotes, PCD appears to be universally present and indeed should be regarded as one of the hallmarks of the multicellular state itself. ${ }^{5}$ From a purely systemic point of view, PCD in a multicellular organism appears to be just as inevitable as law enforcement in a state. In any differentiated community (of specialized cells or of citizens), rogue elements will necessarily emerge in as (pre)cancerous cells with impaired division control or as criminals with impaired social responsibility, and to protect the community, these need to be subdued or destroyed by dedicated agencies. Those agencies also contribute to the defense against invaders, such as viruses, pathogenic bacteria or rival states, and, at least in the case of PCD, to the normal development of the multicellular organism. ${ }^{6}$ In a sense, the teleology of the emergence of the eukaryotic apoptosis machinery may be best described in terms of the anthropic principle: ${ }^{7}$ eukaryotes had to come up with a PCD systems in order for any complex form of multicellularity to emerge and, accordingly, for us to be here and ponder the mysteries of biological evolution, the origin of apoptosis among them.

Thus, the question that needs to be addressed regarding the origin of eukaryotic PCD is not so much why, but how, i.e. where have the suitable components for the making of the apoptosis molecular machinery come from and what particular innovation(s) did it take to piece them together? Three, not mutually exclusive, principal paths can be envisaged for the origin of eukaryotic functional systems that do not have obvious counterparts in prokaryotes: (i) a cryptic prokaryotic precursor, i.e. an ancestral system in prokaryotes with the same or similar function as the novel eukaryotic system, that has not been studied experimentally, but could be recognized via comparative genomics; (ii) recruitment of prokaryotic proteins (domains) whose original biological function(s) in prokaryotes are unrelated to the new function(s) in eukaryotes, but whose biochemical activities could be employed towards that function (exaptation); ${ }^{8}$ (iii) evolution of new, eukaryotes-specific proteins (domains) for the new functions. In case prokaryotic 
contributions to a particular eukaryote-specific system are detectable, another important question to address is whether these contributions belong to the ancestral, archaeo-eukaryotic heritage or were they acquired from a bacterial source via horizontal gene transfer (HGT). The eukaryotic genome is a chimera of at least two prokaryotic genomes, those of the archaea-like ancestor of the eukaryotic lineage and of an $\alpha$-proteobacterium that gave rise to the mitochondrion via endosymbiosis. ${ }^{9-11}$ In plants, genes coming from a cyanobacterium, the pro-chloroplast endosymbiont, make up an obvious second wave of bacterial invasion. ${ }^{12}$ However, it appears likely that the bacterial input to the making of the eukaryotic genome was not limited to these two major infusions, but rather involved many more piecemeal acquisitions of bacterial genes from more transient symbionts and parasites, particularly at the early stages of eukaryotic evolution. ${ }^{13,14}$

Here we re-examine and extend the results of our previous studies on the provenance of the molecular components of the eukaryotic PCD machinery and the role of each of the above processes in its origin and evolution. $^{15,16}$ The central conclusion is that infusion of bacterial genes, coming from mitochondria, but possibly also from other sources, including Actinomycetes, was indispensable for the emergence of the apoptotic system.

\section{Phyletic patterns of the apoptotic machinery components}

These days, with multiple, complete genome sequences from various walks of life available for analysis, it is natural to start an evolutionary study of any functional system with a comprehensive, genome-oriented inventory of its components. Producing such an inventory is a straightforward, but not necessarily easy task because, for the results to be meaningful, one needs to apply the most powerful methods for protein sequence and, on some occasions, structure analysis to identify even those homologs, in which sequence conservation has been (virtually) erased, and to distinguish orthologs (direct evolutionary counterparts) from paralogs (genes related by duplication). More specifically, application of such methods and careful analysis of the results were critical for the identification of the prokaryotic homologs of some quintessential eukaryotic proteins. The prokaryotic counterparts of actin and tubulin are early examples of such fundamental findings that were first made by sequence analysis and subsequently confirmed by determination of the structures of the respective bacterial proteins. ${ }^{17-19}$ The identification of bacterial homologs of eukaryotic DNA primase and DNA-binding protein $\mathrm{Ku}$ is a more recent result of the ongoing search for crucial eukaryote-prokaryote connections. ${ }^{20,21}$ The salient computational approaches have been repeatedly discussed elsewhere and here we are not going into any details, referring the reader to these sources. $22-27$

The results of such a genomic census can be conveniently conceptualized and presented in the form of phyletic patterns, i.e. patterns of presence/absence of the given group of orthologous genes or a given domain in the genomes of species from all sampled taxa. ${ }^{28-30}$ Examina- tion of phyletic patterns is no substitute for traditional and new methods of phylogenetic analysis, but it is extremely useful as a means for obtaining a first approximation of the evolutionary scenario for a given protein or domain and as a tool for functional inference. ${ }^{31}$

The phyletic patterns for the key components of the eukaryotic PCD system are compiled in Table 1. The metapattern emerging from the comparison of these patterns is clear-cut: the enzymes involved in apoptosis tend to show a broad phyletic distribution, with bacterial homologs identifiable, whereas the non-enzymatic components are less conserved and are often limited in their distribution to only one eukaryotic lineage (Table 1). A notable exception is the Toll-interleukin-receptor (TIR) domain, which is present not only in both plants and animals, but also in many bacterial species. The feature of these patterns that appears to be critical for our understanding of the origin and evolution of eukaryotic PCD is that, with the single notable exception of the Apoptosis-Inducing Factor (AIF), the prokaryotic homologs of the proteins involved in PCD are widely represented in bacteria, but not in archaea. The only other exception is the presence of a predicted AP-ATPase in the archaeon Pyrococcus horikoshii, but this is readily attributable to HGT from a bacterial source (see below). In and by itself, this pattern suggests the possibility of a substantial contribution of acquired bacterial genes to the evolution of the eukaryotic PCD system. In the following sections of this study, we assess this hypothesis through a more detailed examination of the prokaryotic homologs of the eukaryotic proteins involved in PCD and phylogenetic analysis of the corresponding protein families.

\section{Phylogenetic analysis of the PCD machinery components that have prokaryotic homologs}

\section{The caspase superfamily proteases}

Caspases are the principal proteases that are activated during animal apoptosis and mediate cleavage of a variety of proteins ultimately leading to cell disintegration. ${ }^{32,33}$ Caspases have undergone remarkable proliferation and specialization in vertebrates, in which they function in a cascade including several cleavage events. Structural comparisons showed that caspases belong to a distinct class of cysteine proteases, which also includes hemoglobinases, gingipains and clostripains (hereinafter CHF-class, after CaspaseHemoglobinase Fold). Recent studies that involved a combination of in-depth sequence analysis, structural analysis and direct experiments revealed a substantially greater diversity of caspase-related proteases than previously suspected. In particular, two families of predicted CHFproteases that are more closely related to the classic caspases than to other proteases of this class, designated paracaspases and metacaspases, were identified. ${ }^{34} \mathrm{~A}$ possible regulatory role for the human paracaspase in PCD has been demonstrated; the functions of metacaspases remain to be investigated, but a major role in $P C D$ in plants is likely, given the proliferation of the genes coding for metacaspases in plant genomes, the absence of other 
Table 1 Domains and proteins involved in apoptosis and related pathways

\begin{tabular}{|c|c|c|c|c|c|c|}
\hline $\begin{array}{l}\text { Protein/domain } \\
\text { family }\end{array}$ & $\begin{array}{l}\text { Vertebrates } \\
\text { (Human) }\end{array}$ & $\begin{array}{l}\text { Arthropods } \\
\text { (Fruit Fly) }\end{array}$ & $\begin{array}{l}\text { Nematodes } \\
\text { (Worm) }\end{array}$ & Plants & $\begin{array}{l}\text { Fungi } \\
\text { (yeasts) }\end{array}$ & $\mathrm{EBE}^{\mathbf{a}}$ \\
\hline \multicolumn{7}{|c|}{ Ligands and receptors } \\
\hline TNFR & 8 & $\mathrm{H}^{\mathrm{b}}$ & $\mathrm{H}$ & $\mathrm{H}$ & 0 & $?$ \\
\hline IL-1 like & 8 & $\mathrm{O}(\mathrm{H})$ & $\mathrm{O}(\mathrm{H})$ & $\mathrm{O}(\mathrm{H})$ & $\mathrm{O}(\mathrm{H})$ & $\mathrm{O}(\mathrm{H})$ \\
\hline Toll-like & 10 & 8 & $1(?)$ & $\mathrm{O}(\mathrm{H})$ & $0(\mathrm{H})$ & $(\mathrm{H})$ \\
\hline TNF & 17 & 1 & $\mathrm{O}(\mathrm{H})$ & 0 & 0 & $?$ \\
\hline Cysteine Knots & $\begin{array}{l}\text { TGF like: } 12 \\
\text { NGF like: } 3\end{array}$ & $\begin{array}{l}\text { TGF like: } 3 \\
\text { Spaetzle like: } 3 \\
\text { NGF like: } 1\end{array}$ & $\mathrm{H}$ & 0 & 0 & $?$ \\
\hline \multicolumn{7}{|c|}{ Adaptors: 6-helical domain } \\
\hline DD & 30 & 9 & 6 & 0 & 0 & $?$ \\
\hline DED & 7 & 1 & 0 & 0 & 0 & $?$ \\
\hline CARD & 20 & 1 & 2 & 0 & 0 & $?$ \\
\hline PYRIN & 8 & 0 & 0 & 0 & 0 & $?$ \\
\hline \multicolumn{7}{|c|}{ Adaptors: other } \\
\hline TIR & 22 & 10 & 1 & $\sim 140$ & 0 & $?$ \\
\hline
\end{tabular}

Prokaryotes

\section{0}

$\mathrm{O}(\mathrm{H})$

0

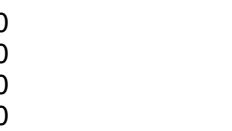

Streptomyces (4)

1 each in

Rhizobium,

Synechocystis,

Caulobacter

crescentus, Bacillus and Anabaena.

\begin{tabular}{|c|c|c|c|c|}
\hline $\begin{array}{l}\text { MATH } \\
\text { (TRAF-like) }\end{array}$ & $\begin{array}{l}6 \text { (several } \\
\text { additional } \\
\text { MATH } \\
\text { domains } \\
\text { not directly } \\
\text { related to } \\
\text { TRAF) }\end{array}$ & $\begin{array}{l}3 \text { (several } \\
\text { additional } \\
\text { MATH } \\
\text { domains } \\
\text { not directly } \\
\text { related to } \\
\text { TRAF) }\end{array}$ & $\begin{array}{l}1 \text { (several } \\
\text { additional } \\
\text { MATH } \\
\text { domains } \\
\text { not directly } \\
\text { related to } \\
\text { TRAF) }\end{array}$ & $\begin{array}{l}\sim 26 \text { MATH } \\
\text { domains but } \\
\text { none } \\
\text { directly } \\
\text { related to the } \\
\text { TRAFs }\end{array}$ \\
\hline BCL-2 family & 11 & 2 & 1 & 0 \\
\hline \multicolumn{5}{|c|}{ Executors: caspase superfamily proteases } \\
\hline Caspases & 14 (one inactive) & 7 & 4 & 0 \\
\hline Paracaspases & 1 & 0 & 1 & 0 \\
\hline Metacaspases & 0 & 0 & 0 & $\sim 10$ \\
\hline
\end{tabular}

1 MATH

domain but none directly related to the TRAFs

\section{0}

1
At least 1

MATH

domain

but none

directly

related to the TRAFS

0

$?$

$?$

1 (Leishmania

Plasmodium

Trypanosome)

\section{0}

(Probable) executors and regulators: other proteases

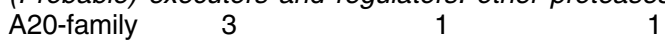

$\begin{array}{lllll}\text { HtrA-family } & \text { At least } 4 & 4 & 6 & \text { At least } 5 \\ \text { AP-ATPase } & 1 & 1 & & \text { Regulators: NTPases }\end{array}$

$\begin{array}{lllll}\text { AP-ATPase } & 1 & 1 & 1 & \sim 190 \\ & & & & \\ \text { NACHT- } & 18 & 1 & 1 & 0 \\ \text { GTPases } & \begin{array}{l}\text { (Naip-like:17, } 1 \\ \text { TP1-like: } 2)\end{array} & (\text { TP1-like: } 2) & (\text { TP1-like: 1) } & \\ & 2 & & & \\ \text { D-GTPase } & 2 & 1 & 2 & \text { Regulators: kinases }\end{array}$

Serine/threonine IKK: 4; DAP: 1; IKK: 2; NIK: 1; DAP: 1; IRAK: $10(\mathrm{H})$ protein kinases NIK: 1; IRAK: 4 IRAK: 1
11
Regulators: BCL-2-family proteins
Several distant Several distant homologs; no orthologs homologs; no orthologs of $\mathrm{A} 20$ 1$$
1
$$

\section{None in yeasts ? \\ but 1 in \\ Neurospora}

None in

yeasts

but 1 TP-like

form is seen in

Podospora and Neurospora

0

$\mathrm{O}(\mathrm{H})$
0
0
Mesorhizobium loti (7), Rhizobium (1) Anabaena (2) Synechocystis (1), M. loti (1), Geococcus (at least 1),

Rhodosphaera (1)

Several distant 1 distant homolog homologs; no in Chlamydophila orthologs pneumoniae of 20

At least $1 \quad 1-8$ (nearly all) bacteria

Streptomyces (9), M.tuberculosis (6) Anabaena (3),

Mesorhizobium (3) Streptomyces (9),

Anabaena (6) Synechocystis (2), Rickettsia conorii (1)

0

$\mathrm{O}(\mathrm{H})$ $\mathrm{Bcl} 2$ 2 1 
Table 1 continued

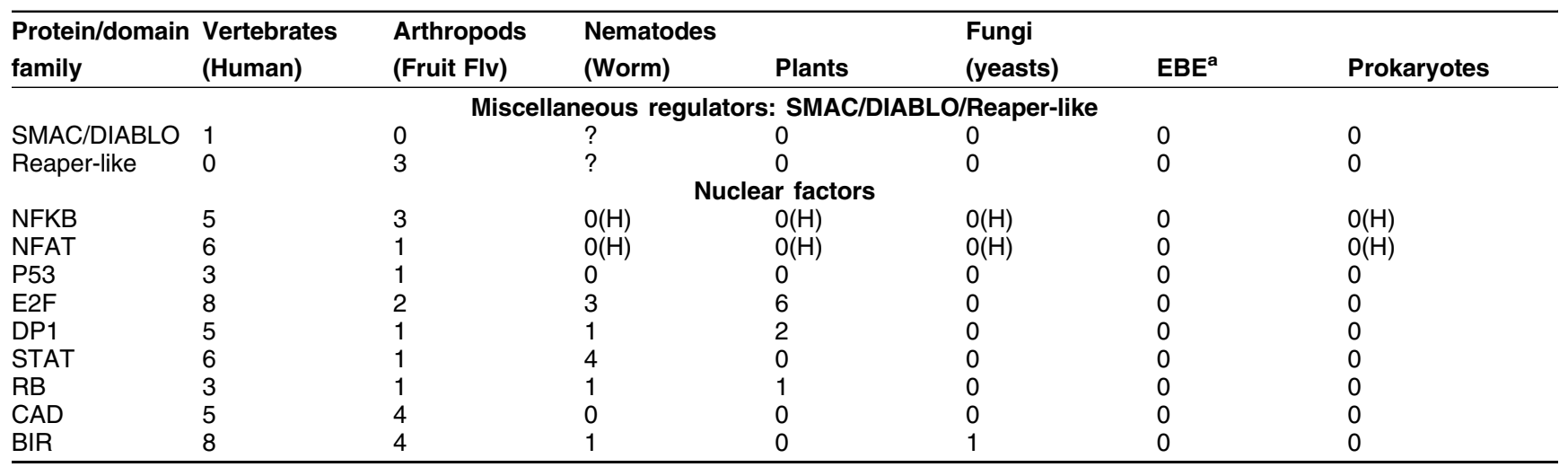

${ }^{a} E B E$, early-branching eukaryotes. ${ }^{b} \mathrm{H}$ : Indicates the presence of homologous domains but no real orthologs

caspase homologs in plants and the fusion of some of the plant metacaspases with the LSD1 Zn-finger, a regulator of PCD in plants. ${ }^{34,35}$ Paracaspases were detected in animals, slime mold, and one group of bacteria, the Rhizobia, with a notable expansion in Mesorhizobium loti, whereas metacaspases are present in plants, fungi, early-branching eukaryotes and a variety of bacteria (Table 1$).{ }^{36}$ Phylogenetic analysis of the caspase-like protease superfamily shows a clear affinity of the eukaryotic metacaspases and paracaspases (together with the classic caspases) with the corresponding predicted proteases from the Rhizobia, which belong to the $\alpha$ subdivision of the Proteobacteria, the free-living ancestors of the mitochondria (Figure 1A). This topology of the phylogenetic tree is best compatible with the origin of metacaspases from the mitochondrial endosymbiont. The case of caspases-paracaspases is more complicated because this branch of the superfamily is not represented so far in eukaryotes other than animals and slime mold. This distribution is compatible with a second, later HGT from $\alpha$ proteobacteria to eukaryotes or with independent loss of the paracaspase gene in multiple eukaryotic lineages.

\section{The OMI (HtrA-like) protease}

The OMI protease homologous to the widespread and wellcharacterized bacterial HtrA family of serine proteases is a recent addition to the repertoire of $P C D$-associated eukaryotic proteins. ${ }^{37-40}$ This protein, normally located in the mitochondria, is released into the cytoplasm during apoptosis and contributes both to caspase-dependent and to caspaseindependent PCD. ${ }^{38}$ HtrA-like membrane-associated proteases are nearly ubiquitous in bacteria, the sole exception so far being the mycoplasmas, the bacterial parasites with the smallest genomes; in contrast, these proteins are missing in most archaeal genomes that have been sequenced to this date. Phylogenetic analysis of the HtrA family (Figure 1B) suggests a major diversification of this family into several distinct lineages in the bacteria with a prominent expansion in $\alpha$-proteobacteria with up to eight members of this family in the genome of Mesorhizobium loti. This analysis strongly supports the monophyly of the eukaryotic OMI/HtrA2 proteases, that are involved in PCD, with a particular lineage of $\alpha$-proteobacterial
HtrA-like proteases (Figure 1B), which is compatible with a mitochondrial origin of the eukaryotic proteins.

\section{Apoptotic (AP)-ATPases and NACHT GTPases}

AP-ATPases are central regulators of PCD that interact with caspases forming the so-called apoptosome and are required for caspase activation. ${ }^{41-43}$ AP-ATPases are present in animals, plants, in which they are encoded by vastly proliferated pathogen resistance genes, one fungal species (Neurospora crassa), many bacteria, and one archaeon, Pyrococcus horikoshii (Table 1). ${ }^{16}$ Among the bacteria, APATPase homologs are present in $\alpha$-proteobacteria, cyanobacteria and Actinomycetes, with a particularly notable proliferation of these proteins in the latter group of bacteria. Phylogenetic analysis of the ATPase domain of AP-ATPases strongly supports the monophyly of the plant and animal representatives, but does not cluster them with any bacterial lineage in particular; in contrast, the Neurospora AP-ATPase clusters with those of Actinomycetes as does the only archaeal member of this family (Figure 1C). The latter two AP-ATPases appear to be obvious cases of HGT from Actinomycetes. In the case of the animal and plant AP-ATPases, no affinity with any particular bacterial lineage was immediately apparent from the tree topology (Figure 1C). However, a more detailed examination of the alignment of the AP-ATPase domain showed that a large subgroup of these proteins, including those from plants and animals together with those from several bacteria, primarily actinomycetes, contained a distinct $\mathrm{C}$-terminal motif, which was missing in the rest of bacterial AP-ATPase homologs, including those from $\alpha$-proteobacteria (Figure 1C and data not shown). This feature allows us to tentatively root the AP-ATPase tree and hence establish the connection between eukaryotic AP-ATPases and homologs from Actinomycetes. Given these observations and the absence of AP. ATPases from the available genome sequences of yeasts and early-branching eukaryotes, a relatively late, around the time of animal-plant divergence, acquisition of this gene by eukaryotes from Actinomycetes seems to be the most likely evolutionary scenario. In principle, however, transfer of the AP-ATPase from mitochondria cannot be ruled out, assuming that the $\alpha$-proteobacterial progenitor of the mitochondria, unlike 


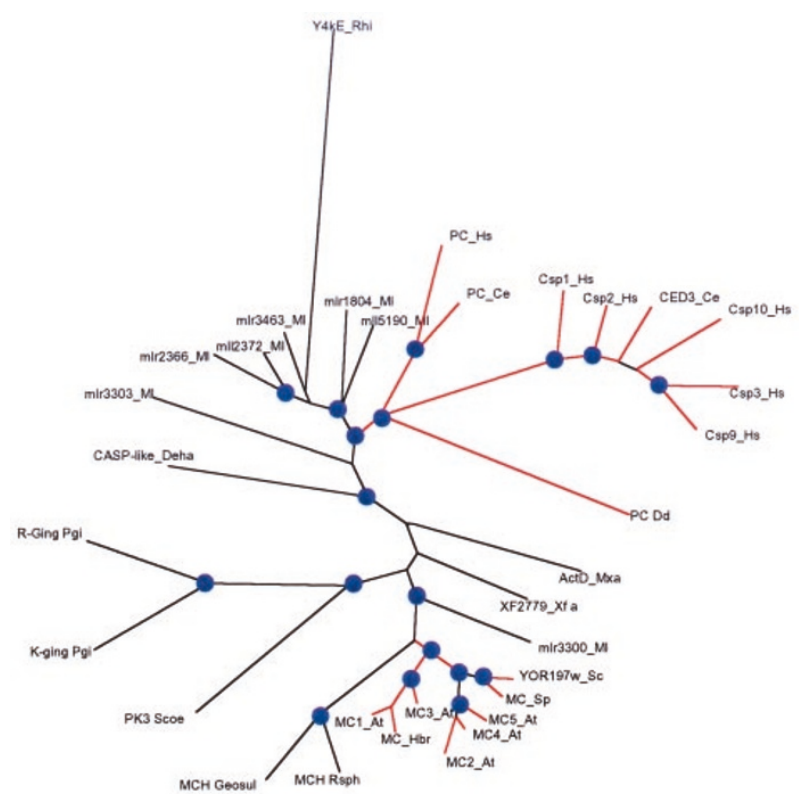

C

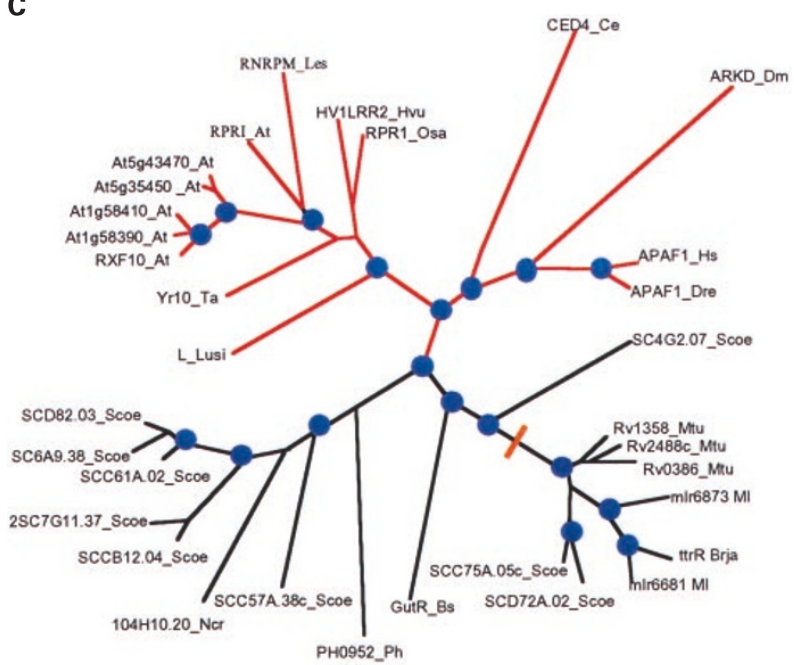

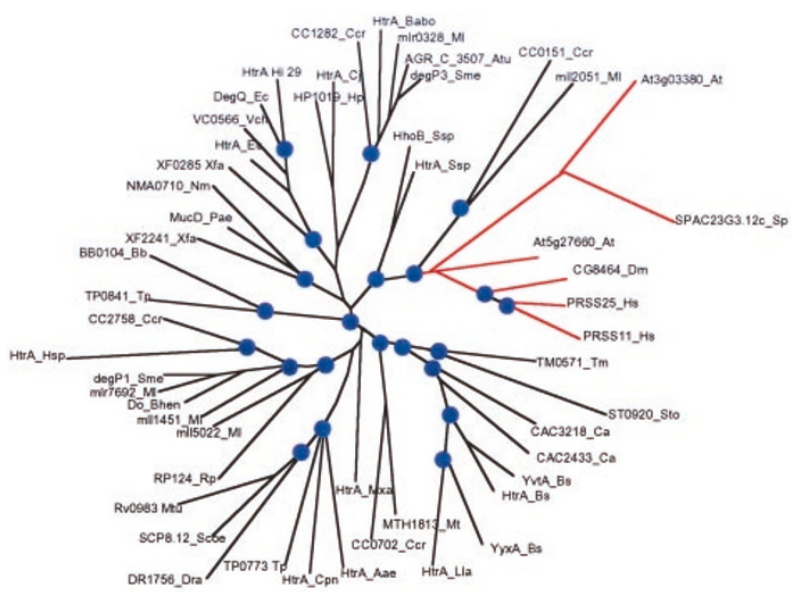

D

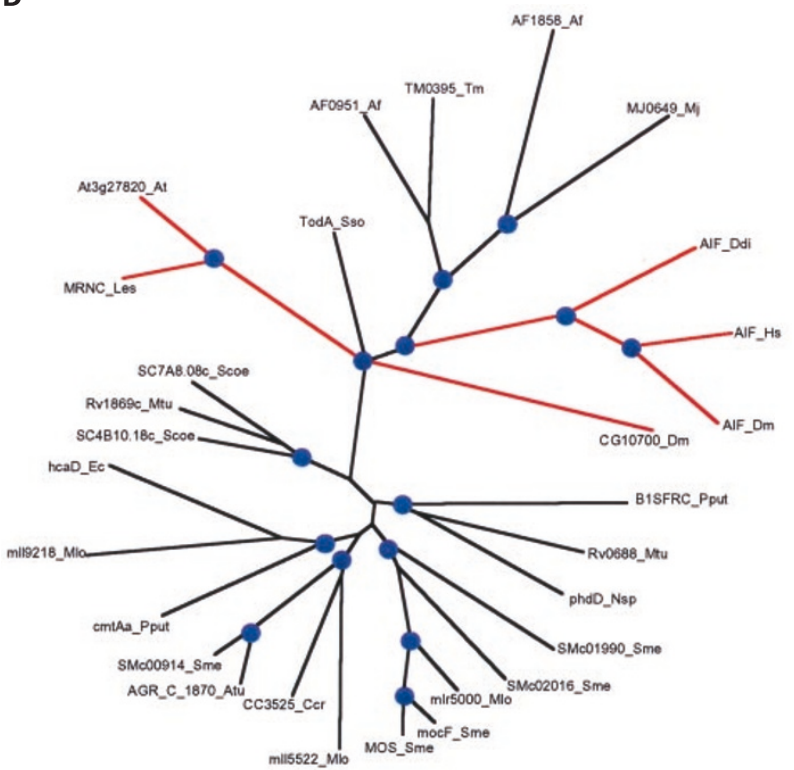

Figure 1 Phylogenetic trees for PCD-associated proteins and their prokaryotic homologs. (A) The caspase-like protease superfamily. (B) The HtrA-like protease family. (C) AP-ATPases. (D) Apoptosis-inducing factor (AIF). Multiple alignments of protein sequence were constructed using the T-Coffee program ${ }^{76}$ (the alignments are available from the authors upon request) and adjusted manually on the basis of PSI-BLAST search results. ${ }^{77}$ Preliminary trees were generated using the least squares ${ }^{78}$ and neighbor joining methods ${ }^{79}$ as implemented in the Phylip package ${ }^{80}$ These trees were used as seeds for local rearrangements to converge on the maximum-likelihood topology using the Protml program of the Molphy package. ${ }^{81}$ They were re-sampled with 10000 bootstrap (RELL-BP) replicates. ${ }^{82}$ The consensus of these trees is shown, with nodes that were recovered in at least $75 \%$ of the bootstrap replicates indicated by circles. The orange bar in (C) separates the distinct branch of AP-ATPases that lack the signature C-terminal motif from the rest of the family. The proteins are designated by the names of the corresponding genes and abbreviated species names. Abbreviations: Hs, Homo sapiens; Mm, Mus musculus; Dre, Danio rerio; Dm, Drosophila melanogaster, $\mathrm{Ce}$, Caenorhabditis elegans; Sc, Saccharomyces cerevisiae; Sp, Schizosaccharomyces pombe; Ncr, Neurospora crassa; At, Arabidopsis thaliana; Dd, Dictyostelium discoideum; Sso, Sulfolobus sulfotaricus; Sto, Sulfolobus tokodaii; Mj, Methanococcus jannaschii; Mta, Methanobacterium thermoautotrophicum; Af, Archaeoglobus fulgidus; Ph, Pyrococcus horikoshii; Ap, Aeropyrum pernix; Atu, Agrobacterium tumefaciens; Pae, Pseudomonas aeruginosa; Pput, Pseudomonas putida; Babo, Brucella abortus; Bs, Bacillus subtilis; Bhen, Bartonella henselae; $\mathrm{Ca}$, Clostridium acetylbutylicum; Ccr, Caulobacter crescentus; Cj, Campylobacter jejuni; Dehalo, Dehalococcoides species; Ec, Escherichia coli; Geosul, Geosulfurococcus; Hp, Helicobacter pylori; MI, Mesorhizobium loti; Mxa, Myxococcus xanthus; Pgi, Porphyromonas gingivalis, Rhi, Rhizobium species; Rp, Rickettsia prowazekii; Ssp, Synechocystis sp.; Scoe, Streptomyces coelicolor, Sme, Sinorhizobium meliloti; Tm, Thermotoga maritima; Tp, Treponema pallidum; Xf, Xylella fastidiosa 
Rhizobia, had an AP-ATPase with the C-terminal motif and that some eukaryotic lineages have lost this gene.

The NACHT (after NAIP, IIA, 트T-E and IP1) family is another group of NTPases (primarily, if not exclusively, GTPases) with a eukaryotic-bacterial phyletic pattern. ${ }^{44}$ So far, this family is represented in animals, one fungal species (Podospora anserina) and several bacterial species (Table 1). A major proliferation of the NACHT family associated with an involvement in PCD and immune response against diverse viral and bacterial pathogens is observed only in vertebrates, whereas other animals have only one NACHT domain that appears to be involved in the telomerase function rather than apoptosis. ${ }^{16,44-47}$ Typically, the same bacteria that have AP-ATPases tend to encode NACHT NTPases, sometimes multiple ones (Table 1). In the general scheme of evolution of NTPases, the NACHT family appears to be the sister group of AP-ATPases. ${ }^{44}$ Thus, given the considerable diversification of each of these families in bacteria, the divergence between them should date to a relatively early stage of bacterial evolution. In the recently sequenced genome of the $\alpha$-proteobacterium Rickettsia conorii, ${ }^{48}$ we detected a bacterial member of the NACHT family (gene RC0370 product) that is particularly closely related to the vertebrate, NAIP-like NACHT NTPases. This close relationship to vertebrate proteins and presence in a single species of Rickettsia suggests acquisition of a host gene by the intracellular parasite as the most likely scenario. Although the low sequence conservation within the NACHT family makes it a poor candidate for phylogenetic analysis, two distinct groups could be discerned within this family. The first group includes the vertebrate-specific expansion of NAIP-like proteins, Rickettsial RC0370, and several other bacterial proteins from Streptomyces and Anabaena; the second group includes the animal TP-1-like telomerase subunits and the fungal proteins Het-E-1 from Podospora anserina and B24M22.200 from Neurospora crassa. This implies that multiple HGT events might have been responsible for the introduction of these proteins in eukaryotes, one occurring early in evolution and resulting in the TP-1-like forms and the second one occurring much later, perhaps even just prior to the emergence of the vertebrate lineage, and injecting the NAIP-like forms. If the latter scenario were to be correct, then the form in Rickettsia conorii might represent a close homolog of the potential bacterial gene involved in such a lateral transfer event.

\section{Apoptosis-inducing factor (AIF)}

Apoptosis-inducing factor (AIF) is a mitochondrial protein that is released into the cytoplasm during apoptosis and stimulates a caspase-independent PCD pathway, which is essential for early morphogenesis in mammals. ${ }^{49,50}$ This function of AIF is highly conserved in evolution as evidenced by the recent characterization of AIF in the slime mold Dictyostelium discoideum. ${ }^{51}$ AIF is a Rossmann-fold, FAD-dependent oxidoreductase, but the redox activity is not required for its pro-apoptotic function. ${ }^{52}$ This protein is highly conserved and nearly ubiquitous in all three primary kingdoms, bacteria, archaea and eukaryotes. Phylogenetic analysis showed that eukaryotic AIFs cluster with their archaeal orthologs, to the exclusion of bacterial ones (with the sole exception for Thermotoga maritima, a hyperthermophilic bacterium that probably received this gene from archaea via HGT) (Figure 1D). Thus, AIF seems to be the only major component of the apoptosis apparatus that conforms with the standard model of evolution whereby the phylogeny of a gene inherited from the last universal common ancestor follows the tree topology with the primary radiation of the archaeo-eukaryotic and bacterial clades. This is particularly notable in the case of AIF because this is an ancestral protein that was secondarily recruited for a mitochondrial function.

\section{Other ancient apoptotic proteins}

The TIR domain is the only PCD adaptor molecule ${ }^{53}$ that has been detected in bacteria, although not so far in fungi or earlybranching eukaryotes. ${ }^{15}$ The distribution of the TIR domain in bacteria is similar to that seen for caspase-related proteases, AP-ATPases and NACHT NTPases, with a notable expansion in Actinomycetes. The information contained in the TIR domain alignment does not seem to be sufficient to produce a reliable phylogenetic tree. Nevertheless, given that TIR domains seem to be present only in crown-group eukaryotes, possible evolutionary scenarios include a mitochondrial acquisition with subsequent loss in multiple eukaryotic lineages or a later HGT from a bacterial source.

BCL-2 family proteins are important positive and negative regulators of $P C D$. At least one of the mechanisms of action of these proteins involves integration into the mitochondrial membrane resulting in activation or suppression of cytochrome $c$ release from the mitochondria. ${ }^{54} \mathrm{BCL}-2$ protein sequences are relatively poorly conserved and no prokaryotic homologs were detected despite extensive sequence searches. However, structurally, BCL-2 resembles the membrane translocation domains of certain bacterial toxins, such as diphteria toxin and colicins, to the extent that a common origin appears to be a possibility. ${ }^{55,56}$

\section{Bacterial homologs of eukaryotic PCD-associated proteins: domain architectures suggest functional interactions}

Functional information on bacterial homologs of eukaryotic apoptotic proteins is scarce. Effectively, the only available data point to a role of some of these proteins, such as GutR from Bacillus subtilis and AfsR from Streptomyces coelicolor, in transcription regulation. ${ }^{57,58}$ The GutR protein, which is a regulator of the glucitol operon, has been shown to function in an ATP-dependent manner. ${ }^{59}$ The AfsR protein is a global regulator of physiological and morphological differentiation in Streptomycesand is itself regulated by reversible phosphorylation catalyzed by the serine-threonine kinase AfsK. ${ }^{60,61}$ Among the numerous caspase-related proteins detected in bacteria, only one, a generic caspase homolog roughly equidistant from paracaspases and metacaspases, has been characterized experimentally. This protein, ActD from Myxococcus xanthus, is a regulator of the production of the sporulation morphogen, CsgA, but its mechanism of action remains unknown. ${ }^{62}$ 


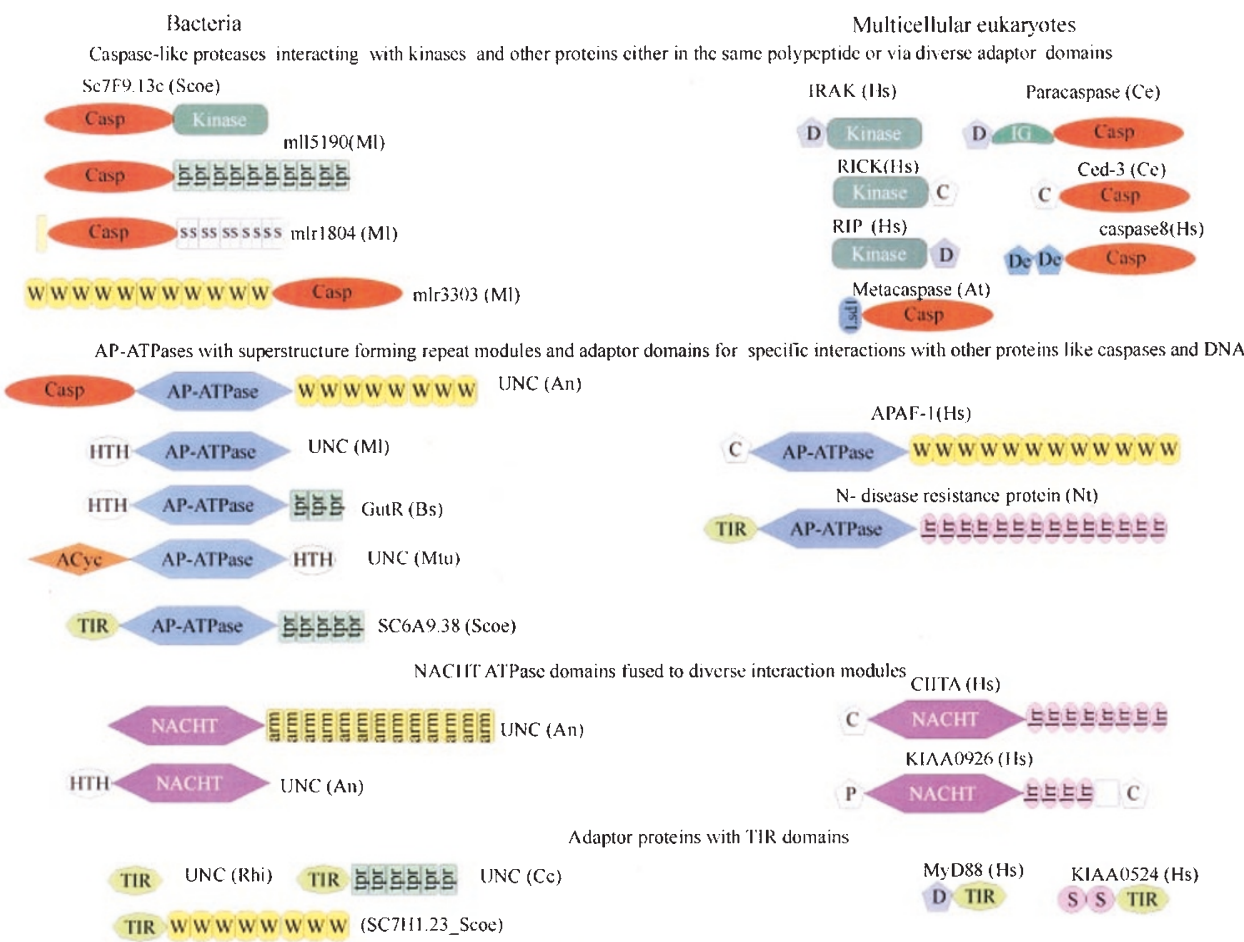

Figure 2 Comparison of the analogous architectures of eukaryotic and bacterial multi-domain proteins with conserved modules involved in the PCD machinery. The bacterial proteins are shown to the left and eukaryotic proteins to the right; the proteins are broadly grouped on the basis of the principal shared domains. The proteins are indicated by their name and the abbreviation of the species of origin (same as in the legend to Figure 1) is indicated in parentheses. The uncharacterized proteins from various bacterial species are denoted by UNC. The domain name abbreviations: Acyc, Adenylyl cyclase; Casp, Caspase; D, Death domain; De, Death effector domain; C, Card domain; P-Pyrin domain; Ig, Immunoglobulin domain; S, SAM domain; HTH, Helix-Turn-Helix domain; TIR, Toll-IL1 receptor domain; W, WD40 propeller domain; Irr, leucine-rich repeat; Arm, Armadillo repeat; tpr, tetratricopeptide repeat; s, Sel-1 repeats; Lsd-1, plant hypersensitive response protein LSD1-like $\mathrm{Zn}$-finger domain. The Mesorhizobium protein $\mathrm{mlr} 1804$ has a signal peptide indicated by a yellow rectangle at the $\mathrm{N}$-terminus

In contrast to this paucity of experimental data, examination of the domain architectures of the bacterial homologs of apoptotic components provides tantalizing functional hints. First, nearly all of these proteins form complex, multidomain architectures (Figure 2). Second, many of them contain repetitive protein-protein interaction modules, such as WD40, TPR and Armadillo repeats, which tend to form scaffolds facilitating the formation of large, multisubunit complexes. Finally, and most strikingly, some of the bacterial apoptosis-related proteins are fused within the same multidomain proteins, suggesting functional interactions between them. Examples include fusion of a caspase-like protease with an AP-ATPase (and WD40 repeats) in the cyanobacterium Anabaena and the TIR-AP ATPase and AP-ATPase-Adenylyl cyclase fusions in Actinomycetes (Figure 2). Some of the domain architectures observed among apoptotic protein homologs in bacteria reflect the specifics of prokaryotic signal transduction; examples include the characteristic fusions of APATPases with helix-turn-helix DNA-binding domains in transcription regulators (Figure 2). These peculiarities notwithstanding, the above observations are sufficient to substantiate a proposition that bacterial homologs of the apoptotic proteins interact functionally and, most likely, also physically in signal-transduction pathways whose exact nature remains to be determined. A bolder speculation would hold that, in bacteria with complex development and differentiation, such as Actinomycetes, Cyanobacteria, Myxobacteria and some $\alpha$-proteobacteria, ${ }^{63-66}$ the homologs of apoptotic proteins, in particular caspases and APATPases, form large complexes that might be functional analogs or perhaps even evolutionary predecessors of the eukaryotic apoptosome. ${ }^{41,67} \mathrm{~A}$ search for such a complex in bacteria and elucidation of its potential role in signal transduction and/or an as yet undiscovered form of PCD seems to be an exciting subject for experimental studies.

\section{A brief history of eukaryotic programmed cell death: the case for multiple infusions of bacterial genes}

As noticed previously ${ }^{15,16}$ and detailed above, the principal enzymes and at least one adaptor domain involved in eukaryotic PCD are widespread in bacteria, but conspicuously missing in archaea. Furthermore, at least two important lines of evidence support HGT from bacteria to eukaryotes as the principal route of evolution of these proteins. First, in at least two cases, those of OMl and metacaspases, phylogenetic analysis shows an affinity of the eukaryotic apoptotic proteins with homologs from $\alpha$-proteobacteria. Given that the endosymbiont that gave rise to the mitochondrion undoubtedly was an $\alpha$-proteobacterium,,$^{10,68}$ these observation are to be interpreted as strong evidence of a mitochondrial origin for the respective genes. Second, exploration of the bacterial 
homologs of apoptotic proteins in each case, and particularly for caspase-related protease and AP-ATPases, reveals a greater diversity, in terms of phyletic distribution, domain architectures and sequences themselves, than seen in eukaryotes (Figure $2^{36}$; L Aravind and EV Koonin, unpublished). This suggests the likely direction for HGT: from bacteria to eukaryotes.

When considering the bacterial contribution to the origin of the eukaryotic PCD systems, it is impossible to overlook the major role mitochondria have in apoptosis. Indeed, mitochondria appear to be among the principal (if not the principal) sensors of cell damage that trigger PCD by releasing cytochrome $c$, which stimulates apoptosome assembly. ${ }^{67,69,70}$ Furthermore, as discussed above, additional proteins, such as AIF, OMI and SMAC/DIABLO, ${ }^{71,72}$ are released from the mitochondria and also contribute to PCD. Is there an intrinsic connection between the role of mitochondria in PCD and the origin of the apoptotic system itself? This is not immediately obvious, in part because the involvement of mitochondria in apoptosis has been demonstrated primarily in the vertebrate model system, potentially allowing for the possibility that mitochondria are a late addition to the ancestral repertoire of apoptotic mechanisms. However, several recent studies suggest that the mitochondrial contribution to PCD is likely to be ancient, e.g. the aforementioned data on the role of AIF in PCD in slime mold $^{51}$ and the demonstration of the role of mitochondrial endonuclease $G$ in apoptotic DNA degradation in the nematode $C$. elegans ${ }^{73}$; indications of a mitochondrial involvement in PCD in plants also start to accumulate. $^{74,75}$ The other side of the problem is that mitochondrial endosymbiosis and the origin of PCD appear to be uncoupled in time because endosymbiosis, a very early event in eukaryotic evolution, apparently was followed by a lengthy age of unicellular eukaryotes, which do not seem to have PCD. Thus, mitochondrial acquisitions, such as AIF and metacaspase, must have been pre-adaptations for PCD, which originally had other roles in primitive eukaryotes, and only later were exapted for their functions in apoptosis.

In principle, all bacterial contribution to eukaryotic PCD could be explained through acquisition of mitochondrial genes. However, this would require multiple losses of the genes for apoptotic proteins in different eukaryotic lineages and, in addition, would be at odds with some phylogenetic analysis results, e.g. those that seem to link AP-ATPases with Actinomycetes. Thus, a different scenario, with at least two infusions of bacterial genes contributing to the origin of PCD, appears to be more parsimonious. The first influx of the relevant bacterial genes was part of the domestication of the pro-mitochondrial endosymbiont, whereas the second one probably occurred at the stage of the primitive multicellular eukaryote, perhaps the ancestor of the eukaryotic crown group; at least occasional subsequent gene transfers also occurred, such as acquisition of APATPase by the fungus $N$. crassa, and perhaps even the less orthodox acquisition of an additional NACHT NTPase at a late stage of animal evolution (Figure 3 and see above). Transfer of genes from different bacterial sources does not seem to be incompatible with what is known about

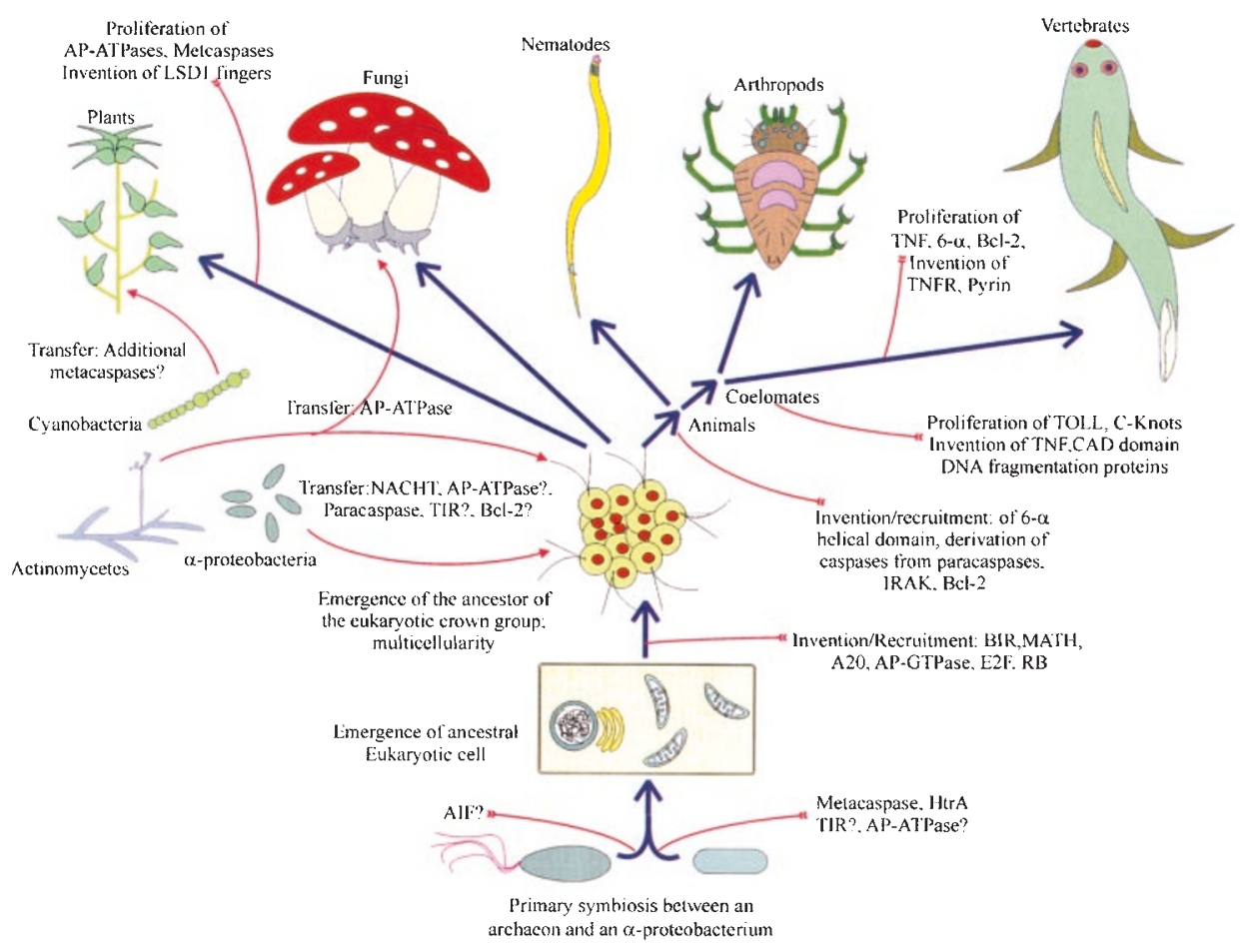

Figure 3 A simplified scheme of the origin and evolution of the eukaryotic PCD system. Blue, thick arrows indicate vertical evolution; red arrows indicate horizontal genes transfer, and red connectors (no arrow heads) indicate recruitment or derivation of eukaryote- specific domains (proteins) 
evolution of primitive eukaryotes, with their various bacterial symbionts. $^{13}$

Proteins encoded by scavenged bacterial genes appear to constitute the core of the apoptotic machinery; a caspase-like protease, probably a metacaspase, an HtrAlike protease and AP-ATPases were principal enzymatic components, whereas TIR domain might have functioned as the main adaptor. The core components have undergone further, lineage-specific proliferation and specialization, such as expansion of caspases in vertebrates and metacaspases and AP-ATPases in plants. Around this core, the outer layers of the apoptotic machinery have built up gradually from exapted domains that originally might have had different functions, such as MATH or BIR, and of newly invented domains, such as the six-helical adaptor domain, which subsequently gave rise to Death, Death effector, and CARD domains(Figure 3).

Coming back to the three routes of eukaryotic innovations listed in the beginning of this study, we clearly see that routes ii and iii, exaptation of bacterial and perhaps a few ancestral archaeo-eukaryotic proteins for new functions and invention of novel domains, contributed substantially to the evolution of PCD. Whether or not route $i$, direct recruitment of a bacterial precursor, was also employed, remains to be established through functional characterization of the bacterial homologs of apoptotic proteins.

The observations described here emphasize the pivotal role of bacterial-eukaryotic HGT in the origin of the eukaryotic PCD system and, by implication, of the eukaryotic multicellularity itself. Indeed, much of the glory of eukaryotic ascension to the ultimate complexity of higher plants and animals might owe to a lucky choice of bacteria with complicated differentiation processes as the primary, promitochondrial, and perhaps subsequent symbionts.

\section{Note added in proof}

After submission of the manuscript of this study, it came to our attention that mitochondrial endosymbiosis and the origin of eukaryotic PCD could be linked in a straightforward hypothesis. The early $\alpha$-proteobacteria endosymbionts might have been using secreted and membrane proteases, such as metacaspases, paracaspases and HtrA-like proteases, to kill their host cells once those became unhospitable environments, e.g. because of scarcity of nutrients. Such a mechanism could enable the endosymbionts to efficiently use the corpse of the assassinated host and move to another host. During subsequent evolution, this weapon of aggression might have been appropriated by the host and made into a means of programmed suicide, with the subsequent addition of regulatory components. In general terms, this idea has been proposed by Frade and Michaelidis (Frade JM, Michaelidis TM (1997) Origin of eukaryotic programmed cell death: a consequence of aerobic metabolism? Bioessays 19: 827-832).

\section{Acknowledgements}

Not only the entire body of current literature on PCD, but even the subset that is directly relevant to the subject of the bacterial contribution to the origin and evolution of apoptosis, is vast. We appreciate the important work of all researchers in this area and apologize to those whose publications are not cited or are cited incompletely due to space considerations or to our inexcusable ignorance. This article is a 'United States Government Work' paper as defined by the US Copyright Act.

\section{References}

1. Maynard Smith J and Szathmary E (1997) The major transitions in evolution. Oxford: Oxford University Press

2. Yarmolinsky MB (1995) Programmed cell death in bacterial populations. Science 267: $836-837$

3. Engelberg-Kulka $\mathrm{H}$ and Glaser $\mathrm{G}$ (1999) Addiction modules and programmed cell death and antideath in bacterial cultures. Annu. Rev. Microbiol. 53: 43-70

4. Lewis K (2000) Programmed death in bacteria. Microbiol. Mol. Biol. Rev. 64: $503-514$

5. Skulachev VP (2001) The programmed death phenomena, aging, and the Samurai law of biology. Exp. Gerontol. 36: 995-1024

6. Meier P, Finch A and Evan G (2000) Apoptosis in development. Nature 407: 796-801

7. Barrow JD and Tipler FJ (1988) The anthropic cosmological principle. Oxford: Oxford University Press

8. Gould SJ (1997) The exaptive excellence of spandrels as a term and prototype. Proc. Natl. Acad. Sci. USA 94: 10750-10755

9. Gray MW (1999) Evolution of organellar genomes. Curr. Opin. Genet. Dev. 9: $678-687$

10. Gray MW, Burger G and Lang BF (2001) The origin and early evolution of mitochondria. Genome Biol. 2; Reviews 1018

11. Berg OG and Kurland CG (2000) Why mitochondrial genes are most often found in nuclei. Mol. Biol. Evol. 17: 951-961

12. Rujan T and Martin W (2001) How many genes in Arabidopsis come from cyanobacteria? An estimate from 386 protein phylogenies. Trends Genet. 17: $113-120$

13. Doolittle WF (1998) You are what you eat: a gene transfer ratchet could account for bacterial genes in eukaryotic nuclear genomes. Trends Genet. 14:307-311

14. Doolittle WF (1999) Lateral genomics. Trends Cell Biol. 9: M5-M8

15. Aravind L, Dixit VM and Koonin EV (1999) The domains of death: evolution of the apoptosis machinery. Trends Biochem. Sci. 24: 47-53

16. Aravind L, Dixit VM and Koonin EV (2001) Apoptotic molecular machinery: vastly increased complexity in vertebrates revealed by genome comparisons. Science 291: $1279-1284$

17. Bork P, Sander C and Valencia A (1992) An ATPase domain common to prokaryotic cell cycle proteins, sugar kinases, actin, and hsp70 heat shock proteins. Proc. Natl. Acad. Sci. USA 89: 7290-7294

18. van den Ent F, Amos LA and Lowe J (2001) Prokaryotic origin of the actin cytoskeleton. Nature 413: 39-44

19. Nogales E, Downing KH, Amos LA and Lowe J (1998) Tubulin and FtsZ form a distinct family of GTPases. Nat. Struct. Biol. 5: 451-458

20. Koonin EV, Wolf YI, Kondrashov AS and Aravind L (2000) Bacterial homologs of the small subunit of eukaryotic DNA primase. J. Mol. Microbiol. Biotechnol. 2: $509-512$

21. Aravind $L$ and Koonin EV (2001) Prokaryotic homologs of the eukaryotic DNAend-binding protein $\mathrm{Ku}$, novel domains in the Ku protein and prediction of a prokaryotic double-strand break repair system. Genome Res. 11: 1365-1374

22. Bork P and Koonin EV (1998) Predicting functions from protein sequences where are the bottlenecks? Nat. Genet. 18: 313-318

23. BorkP, Dandekar T, Diaz-Lazcoz Y, EisenhaberF, Huynen M and Yuan Y (1998) Predicting function: from genes to genomes and back. J. Mol. Biol. 283: 707-725

24. Altschul SF and Koonin EV (1998) PSI-BLAST - a tool for making discoveries in sequence databases. Trends Biochem. Sci. 23: 444-447

25. Aravind L and Koonin EV (1999) Gleaning non-trivial structural, functional and evolutionary information about proteins by iterative database searches [In Process Citation]. J. Mol. Biol. 287: 1023-1040

26. Durbin R, Krogh A, Mitchison G and Eddy S (1999) Biological sequence analysis: probabilistic models of proteins and nucleic acids. Cambridge: Cambridge University Press 
27. Baxevanis AD and Ouelette BFF (eds.) (2001) Bioinformatics: A practical guide to the analysis of genes and proteins, Second Edition. New York: John Wiley

28. Tatusov RL, Koonin EV and Lipman DJ (1997) A genomic perspective on protein families. Science 278: 631-637

29. Gaasterland T and Ragan MA (1998) Microbial genescapes: phyletic and functional patterns of ORF distribution among prokaryotes. Microb. Comp. Genomics 3: $199-217$

30. Galperin MY and Koonin EV (2000) Who's your neighbor? New computational approaches for functional genomics. Nat. Biotechnol. 18: 609-613

31. Koonin EV, Makarova KS and Aravind L (2001) Horizontal gene transfer in prokaryotes: quantification and classification. Annu. Rev. Microbiol 55: 709742

32. Thornberry NA and Lazebnik Y (1998) Caspases: enemies within. Science 281 $1312-1316$

33. Los M, Stroh C, Janicke RU, Engels IH and Schulze-Osthoff K (2001) Caspases: more than just killers? Trends Immunol. 22: 31-34

34. Uren AG, O'Rourke K, Aravind L, Pisabarro MT, Seshagiri S, Koonin EV and Dixit VM (2000) Identification of paracaspases and metacaspases: two ancient families of caspase-related proteins, one of which plays a central role in MALT lymphoma. Mol. Cell. 6: 961-967.

35. Dietrich RA, Richberg MH, Schmidt R, Dean C and Dangl JL (1997) A novel zinc finger protein is encoded by the Arabidopsis LSD1 gene and functions as a negative regulator of plant cell death. Cell 88: 685-694

36. Aravind $L$ and Koonin EV Classification of the caspase-hemoglobinase fold: detection of new families and implications for the origin of the eukaryotic separins. Proteins (in press)

37. Verhagen AM, Silke J, EkertPG, Pakusch M, Kaufmann H, Connolly LM, Day CL, Tikoo A, Burke R, Wrobel C, Moritz RL, Simpson RJ and Vaux DL (2001) HtrA2 promotes cell death through its serine protease activity and its ability to antagonise inhibitor of apoptosis proteins. J. Biol. Chem. 16: 16

38. Hegde R, Srinivasula SM, Zhang Z, Wassell R, Mukattash R, Cilenti L, DuBois G, Lazebnik Y, Zervos AS, Fernandes-Alnemri T and Alnemri ES (2001) Identification of Omi/HtrA2 as a mitochondrial apoptotic serine protease that disrupts IAP-caspase interaction. J. Biol. Chem. 17: 17

39. Suzuki Y, Imai Y, Nakayama H, Takahashi K, Takio K and Takahashi R (2001) A serine protease, $\mathrm{Htr}$ 2, is released from the mitochondria and interacts with XIAP, inducing cell death. Mol. Cell 8: 613-621

40. Martins LM, laccarino I, Tenev T, Gschmeissner S, Totty NF, Lemoine NR, Savopoulos J, Gray CW, Creasy CL, Dingwall C and Downward J (2001) The serine protease Omi/HtrA2 regulates apoptosis by binding XIAP through a Reaper-like motif. J. Biol. Chem. 15: 15

41. Chinnaiyan AM (1999) The apoptosome: heart and soul of the cell death machine. Neoplasia 1: 5-15

42. Cecconi $F$ (2001) Apaf1 is no longer single. Cell Death Differ 8: 773-775

43. Cecconi F (1999) Apaf1 and the apoptotic machinery. Cell Death Differ 6: 1087 1098

44. Koonin EV and Aravind L (2000) The NACHT family-a new group of predicted NTPases implicated in apoptosis and MHC transcription activation. Trends. Biochem. Sci. 25: 223-224

45. Inohara N and Nunez G (2001) The NOD: a signaling module that regulates apoptosis and host defense against pathogens. Oncogene 20:6473-6481

46. Hoffman HM, Mueller JL, Broide DH, Wanderer AA and Kolodner RD (2001) Mutation of a new gene encoding a putative pyrin-like protein causes familial cold autoinflammatory syndrome and Muckle-Wells syndrome. Nat. Genet. 29:301 305

47. Endrizzi MG, Hadinoto V, Growney JD, MillerWand Dietrich WF (2000) Genomic sequence analysis of the mouse Naip gene array. Genome. Res. 10: 1095-1102

48. Ogata H, Audic S, Barbe V, Artiguenave F, Fournier PE, Raoult D and Claverie JM (2000) Selfish DNA in protein-coding genes of Rickettsia. Science 290: 347 350

49. Bidere $N$ and Senik A (2001) Caspase-independent apoptotic pathways in $T$ lymphocytes: a minireview. Apoptosis 6: 371-375

50. Joza N, Susin SA, Daugas E, Stanford WL, Cho SK, Li CY, Sasaki T, Elia AJ, Cheng HY, Ravagnan L, Ferri KF, Zamzami N, Wakeham A, Hakem R, Yoshida $\mathrm{H}$, Kong YY, Mak TW, Zuniga-Pflucker JC, Kroemer G and Penninger JM (2001) Essential role of the mitochondrial apoptosis-inducing factor in programmed cell death. Nature 410: $549-554$
51. Arnoult D, Tatischeff I, Estaquier J, Girard M, Sureau F, Tissier JP, Grodet A, Dellinger M, Traincard F, Kahn A, Ameisen JC and Petit PX (2001) On the evolutionary conservation of the cell death pathway: mitochondrial release of an apoptosis-inducing factor during dictyostelium discoideum cell death. Mol. Biol. Cell 12: $3016-3030$

52. Miramar MD, Costantini P, Ravagnan L, Saraiva LM, Haouzi D, Brothers G, Penninger JM, Peleato ML, Kroemer G and Susin SA (2001) NADH oxidase activity of mitochondrial apoptosis-inducing factor. J. Biol. Chem. 276: 16391 16398

53. Xu Y, Tao X, Shen B, Horng T, Medzhitov R, Manley JL and Tong L (2000) Structural basis for signal transduction by the Toll/interleukin-1 receptor domains. Nature 408: 111-115

54. Martinou JC and Green DR (2001) Breaking the mitochondrial barrier. Nat. Rev. Mol. Cell Biol. 2: 63-67

55. Muchmore SW, Sattler M, Liang H, Meadows RP, Harlan JE, Yoon HS, Nettesheim D, Chang BS, Thompson CB, Wong SL, Ng SL and Fesik SW (1996) $\mathrm{X}$-ray and NMR structure of human $\mathrm{Bcl}-\mathrm{xL}$, an inhibitor of programmed cell death. Nature 381: 335-341

56. Schendel SL, Montal M and Reed JC (1998) Bcl-2 family proteins as ionchannels. Cell Death Differ. 5: 372-380

57. Floriano B and Bibb M (1996) afsR is a pleiotropic but conditionally required regulatory gene for antibiotic production in Streptomyces coelicolor A3(2). Mol. Microbiol. 21: 385-396

58. Poon KK, Chen CL and Wong SL (2001) Roles of glucitol in the GutR-mediated transcription activation process in Bacillus subtilis: tight binding of GutR to tis binding site. J. Biol. Chem. 276: 9620-9625

59. Poon KK, Chu JC and Wong SL (2001) Roles of glucitol in the GutR-mediated transcription activation process in Bacillus subtilis: glucitol induces GutR to change its conformation and to bind ATP. J. Biol. Chem. 276: 29819-29825

60. Umeyama T, Lee PC, Ueda K and Horinouchi S (1999) An AfsK/AfsR system involved in the response of aerial mycelium formation to glucose in Streptomyces griseus. Microbiology 145: 2281-2292

61. Umeyama T and Horinouchi S (2001) Autophosphorylation of a bacterial serine/ threonine kinase, AfsK, is inhibited by KbpA, an AfsK-binding protein. J. Bacteriol 183: $5506-5512$

62. Gronewold TM and Kaiser D (2001) The act operon controls the level and time of C-signal production for Myxococcus xanthus development. Mol. Microbiol. 40: $744-756$

63. Kaiser D (1999) Cell fate and organogenesis in bacteria. Trends. Genet. 15 273-277

64. Osteras M and Jenal U (2000) Regulatory circuits in Caulobacter. Curr. Opin. Microbiol. 3: 171-176

65. Jenal U (2000) Signal transduction mechanisms in Caulobacter crescentus development and cell cycle control. FEMS. Microbiol. Rev. 24: 177-191

66. Kaiser D (2001) Building a multicellular organism. Annu. Rev. Genet. 35: 103123

67. Adrain C and Martin SJ (2001) The mitochondrial apoptosome: a killerunleashed by the cytochrome seas. Trends. Biochem. Sci. 26: 390-397

68. Rotte C, Henze K, Muller M and Martin W (2000) Origins of hydrogenosomes and mitochondria. Curr. Opin. Microbiol. 3: 481-486

69. Green DR and Reed JC (1998) Mitochondria and apoptosis. Science 281 $1309-1312$

70. Bratton SB and Cohen GM (2001) Apoptotic death sensor: an organelle's alter ego? Trends Pharmacol. Sci. 22: 306-315

71. Srinivasula SM, Datta P, Fan XJ, Fernandes-Alnemri T, Huang Z and Alnemri ES (2000) Molecular determinants of the caspase-promoting activity of Smac/ DIABLO and its role in the death receptor pathway. J. Biol. Chem. 275: 3615236157

72. Chai J, Du C, Wu JW, Kyin S, Wang X and Shi Y (2000) Structural and biochemical basis of apoptotic activation by Smac/DIABLO. Nature 406: $855-$ 862

73. Parrish J, Li L, Klotz K, Ledwich D, Wang X and Xue D (2001) Mitochondrial endonuclease $\mathrm{G}$ is important for apoptosis in C. elegans. Nature 412: $90-94$

74. Lam E and del Pozo O (2000) Caspase-like protease involvement in the control of plant cell death. Plant Mol. Biol. 44: 417-428

75. LamE, PontierD and del Pozo O (1999) Die and let live-programmed cell death in plants. Curr. Opin. Plant Biol. 2: 502-507 
76. NotredameC, Higgins DG and Heringa J (2000)T-Coffee: Anovel method for fas and accurate multiple sequence alignment. J. Mol. Biol. 302: 205-217

77. Altschul SF, Madden TL, Schaffer AA, Zhang J,Zhang Z, Miller W and Lipman DJ (1997) Gapped BLAST and PSI-BLAST: a new generation of protein database search programs. Nucleic Acids Res. 25: 3389-3402

78. Fitch WM and Margoliash E (1967) Construction of phylogenetic trees. Science 155: $279-284$

79. Saitou N and Nei M (1987) The neighbor-joining method: a new method for reconstructing phylogenetic trees. Mol. Biol. Evol. 4: 406-425
80. Felsenstein J (1996) Inferring phylogenies from protein sequences by parsimony, distance, and likelihood methods. Methods Enzymol 266: 418-427

81. Adachi J and Hasegawa M (1992) MOLPHY: Programs for molecular phylogenetics. Tokyo: Institute of Statistical Mathematics

82. Kishino H, Miyata T and Hasegawa M (1990) Maximum likelihood inference of protein phylogeny and the origin of chloroplasts. J. Mol. Evol. 31: 151-160 